\title{
STUDI EVALUASI DAN RENOVASI SISTEM PENTANAHAN DI SEKOLAH MENENGAH KEJURUAN (SMK) NEGERI 1 CIMAHI
}

\author{
Sunarto $^{1 \text { ), }}$, Toto Tohir ${ }^{2)}$, Robert Adriaan Philipus ${ }^{3)}$, Yudi Prana Hikmat ${ }^{4)}$, Trisnawiyana ${ }^{5)}$, Yoseph Santosa ${ }^{6}$ \\ 1-6) Program Studi Teknik Listrik, Jurusan Teknik Elektro, Politeknik Negeri Bandung \\ soen@polban.ac.id ${ }^{1)}$, toto.tohir@polban.ac.id ${ }^{2}$,robert@polban.ac.id ${ }^{3}$,yudipranahikmat@polban.ac.id ${ }^{4}$ \\ trisnawiyana@ polban.ac.id ${ }^{5)}$,Yoseph.santosa@ polban.ac.id ${ }^{6}$
}

\begin{abstract}
This research is a follow-up to the findings of the inspection and grounding testing in PKM 2018 activities. The value obtained exceeds 5 ohms. This is not according to the standards based on the General Requirements for Electrical Installation (PUIL) 2011. In the 2019 PKM program activities, evaluation and renovation studies of the installed earthing system which includes: surveying the location to be grounded, drilling for the position of the electrodes to be installed, installation of electrodes equipped with Bentonic material which functions as a binder so that the electrodes with the ground become one and strong, measurement of the earthing value, perform grounding installation, re-measurement of earthing. The earthing value obtained is much smaller than the previous measurement results of 2.83 ohms in the Electronics Laboratory and 2.72 Ohms at the Automation Laboratory of SMKN 1 Cimahi. It is according to the recommended standard PUIL 2011. The PKM team proposes the management of SMKN 1 Cimahi to carry out a routine maintenance and measurement process twice a year on the newly installed earthing system so that the earthing value remains according to the standard.
\end{abstract}

Keywords: Evaluation, Renovation, Grounding System, PUIL

\section{Pendahuluan}

Permasalahan yang dihadapi mitra diketahui pada pahun 2018 yang lalu dimana pada waktu itu tim dari Program Studi Teknik Listrik Jurusan Teknik Elektro Politeknik Negeri Bandung melaksanakan kegiatan Pengabdian kepada Masyarakat di SMK Negeri 1 Cimahi dengan mengadakan pelatihan dasar K3 Listrik. Kegiatan pelatihan tersebut terdiri dari pembekalan teori dan praktek. Yang dikerjakan dalam kegiatan praktek adalah melakukan pengukuran resistans isolasi PHB (Panel Hubung Bagi) dan pengukuran resistans pentanahan (grounding) istalasi listrik. Ketika praktek pengukuran resistans pentanahan instalasi listrik di laboratorium Program Studi Teknik Listrik Otomasi SMK Negeri 1 Cimahi, nilai resistan pentanahan hasil pengukuran tidak sesuai stadar PUIL 2011 yaitu maksimum 5 Ohm. Dari hasil penemuan tersebut maka pihak mitra meminta agar kegiatan pengabdian kepada masyarakat bisa dilanjutkan tahun berikutnya dengan topik perbaikan pentanahan instalasi listrik sekaligus memberikan pengetahuan tentang pemasangan pentanahan instalasi listrik kepada guru, teknisi, dan siswa di SMK Negeri 1 Cimahi. Untuk memenuhi permintaan pihak mitra maka tim pengusul mencoba memberikan solusi dalam bentuk program pengabdian kepada masyarakat DIPA Polban dengan tema "Evaluasi dan Perbaikan Pentanahan Instalasi Listrik di Sekolah Menengah Kejuruan Negeri (SMKN) I Cimahi". Tujuan dari program ini adalah untuk meningkatkan pengetahuan dan keterampilan guru, teknisi, dan siswa dalam hal evaluasi dan pemasangan instalasi pentanahan untuk instalasi listrik dengan target khusu untuk memperbaiki nilai reistans pentanahan yang tidak sesuai standar PUIL 2011 dan hasil kegiatan tersebut bisa dijadikan artikel ilmiah. Kegiatan tersebut direncanakan dalam rentang waktu 5 hari dan dilaksanakan 8 jam sehari dengan jumlah peserta yang dilibatkan sebanyak 20 orang yang terdiri dari guru, teknisi, dan siswa SMK Negeri 1 Cimahi. Metode yang akan dipakai dalam kegiatan tersebut yaitu dengan pembekalan teori selama sehari ( 8 jam), kemudian 4 hari dilibatkan dalam pemasangan instalasi pentanahan dimulai dari pengeboran untuk elektroda pentanahan, pembuatan bak kontrol, memasang instalasi pentanahan, dan pengukuran niali resistan pentanahan setelah perbaikan instalasi pentanahan. Pada dasarnya sistem pentanahan peralatan adalah pentanahan rangka peralatan yang dihubungkan ke elektroda pentanahan melalui hantaran pentanahan. Elektroda pentanahan dapat berupa batang yang ditanam tegak lurus (Gambar 1) atau ditanam sejajar dengan permukaan tanah, dan berupa lempengan 
atau pelat yang kesemuanya ini dirancang untuk memperoleh nilai tahanan atau resistans pentahanan yang kecil sesuai standar (Sunawar,2013) (Rajagukguk,2010). Untuk memperoleh nilai pentanahan yang kecil tersebut maka diperlukan bahan maupun sifat elektrodanya terutama harus memiliki konduktivitas yang tinggi serta memiliki nilai tahanan jenis yang rendah dengan tujuan agar arus gangguan yang mengalir ke tanah cepat (Rajagukguk,2010).

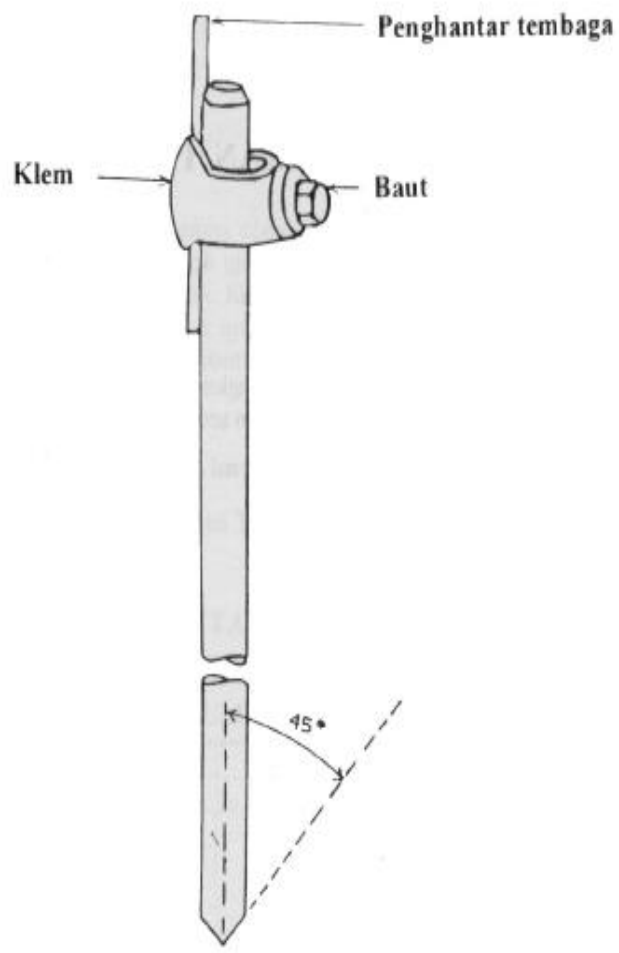

Gambar 1. Konstruksi elektroda batang pembumian tunggal

(Sumber: Rajagukguk,2010)

Elektrode bumi ialah penghantar yang ditanam dalam bumi dan membuat kontak langsung dengan bumi/tanah (SNI 0225. 2011).

Elektroda Pita adalah elektroda yang terbuat dari hantaran berbentuk pita atau berpenampang bulat atau hantaran pilin yang pada umumnya ditanam secara dangkal. Kedalaman pemasangan $0,5 \mathrm{~m}-1,0 \mathrm{~m}$.
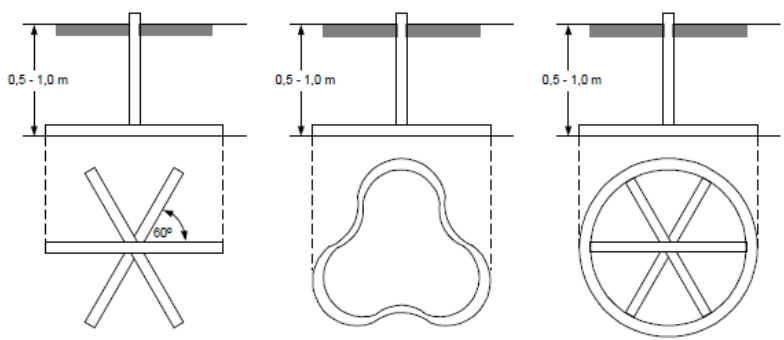

Gambar 2. Cara pemasangan elektroda pita

(Sumber: SNI 0225. 2011).

Elektroda Batang adalah elektroda dari pipa atau besi baja yang dilapisi tembaga yang ditancapkan kedalam tanah secara tegak lurus atau mendatar. Ujung elektroda bentuk batang harus dibuat untuk mempermudah penyebaran arus gangguan ke tanah. Elektroda batang dipancangkan ke dalam tanah dan ujung bawahnya lancip dengan kelancipan $45^{\circ} \pm 5^{\circ}$ (Gambar 1)

Sambungan elektroda pembumian dengan penghantar pembumian harus menggunakan klem dan tidak boleh sambungan mati (dilas atau dipress) (Sunawar,2013), (SNI 0225. 2011). 
Elektroda Pelat adalah elektroda dari bahan pelat logam atau pelat logam berlubang atau dari kawat kasa yang dipasang tegak lurus didalam tanah dengan tepi atasnya sekurang-kurangnya $1 \mathrm{~m}$ dibawah permukaan tanah. Elektrode pelat ialah elektrode dari bahan logam utuh atau berlubang (Sunawar,2013) (SNI 0225. 2011).

Jenis elektrode lain biasanya pipa air yang menggunakan pipa galvanis bisa digunakan sebagai elekjtroda pembumian. Jika jaringan pipa air minum dari logam dipakai sebagai elektrode bumi, maka harus diperhatikan bahwa resistans pembumiannya dapat menjadi besar akibat digunakannya pipa sambungan atau flens dari bahan isolasi (Sunawar,2013) (SNI 0225. 2011).

Perlu diperhatikan elekltroda pentanahan harus tahan terhadap pengaruh korosif. Faktor yang mempengaruhi nilai tahanan pentanahan di suatu tempat adalah tahanan dari elektroda pentanahan, tahanan elektroda pentanahan dengan kontak tanah di sekelilingnya dan tahanan jenis tanah. Masingmasing tanah memiliki karakteristik yang berbeda dikarenakan tanah terdiri dari beberapa lapisan dan masing-masing dari lapisan tersebut berbeda kedalaman, strukturnya, komposisi dan campuran kimiawi yang tidak seragam. Tahanan jenis tanah pada tanah yang sama, cenderung meniliki nilai yang seragam. Faktor lain yang dapat mempengaruhi besaran tahanan jenis tanah adalah faktor suhu tanah, kelembaban tanah dan berapa besar bahan campuran kimiawi yang terkandung dalam tanah tersebut (Sunawar,2013), (Sudiartha,2016) (Setiawan,2018) (Putra,2018) (SNI 0225. 2011). Jadi pentanahan yang benar membuat orang yang berada di sekitar instalasi atau peralatan listrik aman, sementara berfungsi juga melindungi instalasi dan gedung jika terjadi kesalahan arus atau terjadi sambaran petir. Tahanan pentanahan total seluruh sistem tidak boleh lebih dari $5 \mathrm{Ohm}$. Untuk daerah yang tahanan jenis tanahnya sangat tinggi, resistans pentanahan total seluruh sistem boleh mencapai 10 Ohm (SNI 0225, 2000) (Martin, 2018) (Budiman, Mei 2017) (Budiman, November 2017)

Nilai resistansi tersebut diketahui berdasarkan hasil pengukuran menggunakan alat ukur Earth Tester (Putra, 2018), (Rajagukguk, 2010) (Saini, 2016) (Suyanto, 2015) (Siahaan, 2019) (Sukardil, 2019).

Penelitian ini merupakak tindak lanjut dari kegiatan PKM tahun2018, dimana salah satu dari kegiatannnya adalah latihan pengukuran nilai tahanan pentanahan, dan sebagai obyek pengukuran adalah panel instalasi listrik di Laboratotium Otomasi dan hasil pengukuran nilai tahanannya melebihi nilai yang dipersyaratkan dalam PUIL 2011 yaitu maksimum 5 Ohm. Berdasarkan hasil temuan tersebut maka dilanjutkan kegiatan PKM tahun 2019 renovasi sistem pentanahan guna perbaikan nilai tahanan pentanahan instalasi listrik pada laboratorium tersebut.

Tujuan dari penelitian ini adalah melakukan perbaikan terhadap sistem pentanahan instalasi listrik yang tidak sesuai dengan standar karena nilaianya lebih dari $5 \mathrm{Ohm}$. Perbaikan nilai tahanan pentanahan tersebut dilakukan dengan menanam elektroda tambahan. Jenis bahan dan ukuran elektroda pentanahan sangat kecil pengaruhnya terhadap nilai tahanan pentanahan. Yang paling mempengaruji niali tahanan pentanahan adalah tahanan jenis tanah (soil recitivity), jenis jenis dan kelembaban tanah serta kedalaman. Diharapkan dengan mengevaluasi dan menghitung diperoleh nilai sesuai dengan standar PUIL 2011, yaitu maksimum 5 Ohm (SNI 0225. 2011).

\section{Metode}

Penelitian yang dilaksanakan menggunakan metode analitis-komparatif dan deskriptif yaitu menganalisis dari hasil pengujian sebelumnya dengan mengacu pada standar yang berlaku, kemudian hasilnya dibandingkan dengan hasil perhitungan secara teoritis serta melakukan pengamatan terhadap suatu perubahan yang diakibatkan oleh perlakuan terhadap objek serta digambarkan dalam suatu simpulan, seperti yang ditunjukan Gambar 3 Diagram alir penelitian. 


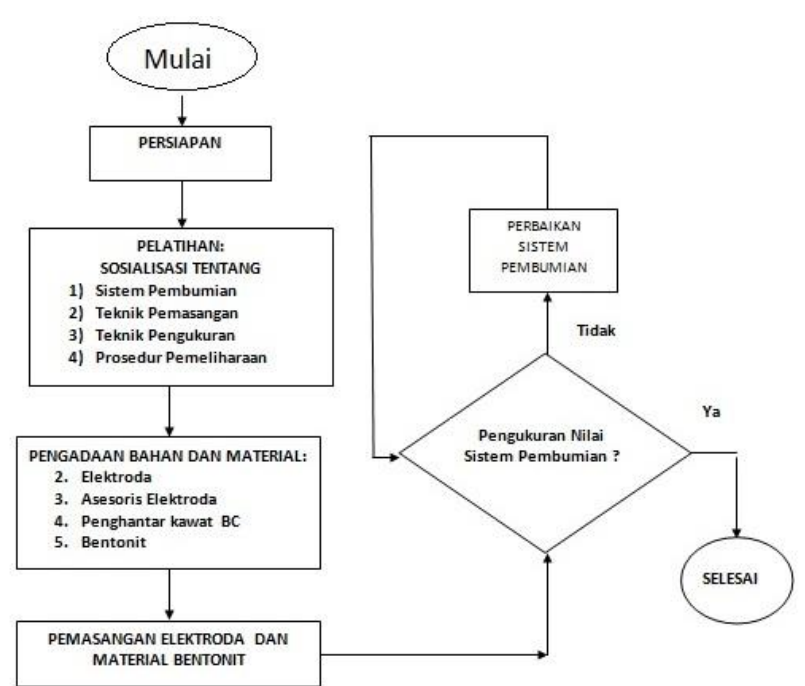

Gambar 3. Diagram alir penelitian

Bahan dan alat penelitian terdiri dari elektroda batang dengan ukuran $5 / 8$ inc, panjang 4 meter dengan bahan tembaga jenis batang, pasir bentonit, kawat BC $35 \mathrm{~mm}^{2}$ dan klem. Alat ukur yang digunakan pada penelitian ini terdiri dari multimeter, Earth tester (pengukur nilai tahanan pentanahan), dan tool set sebagai pendukung.

Proses penelitian dimulai dari persipan; survei ke lokasi yang menjadikan objek penelitian yaitu Laoratorium otomasi di SMKN 1 Cimahi terdiri dari: 1) pengadaan bahan dan alat ukur yang digunakan untuk memasang elektroda pentanahan dan mengukur nilai tahanan pentanahan terpasang apakah sesuai dengan standar atau tidak; 2) pengeboran tanah untuk tempat elektroda pentanahan dipasang; 3)pemasangan elektroda tambahan dan pemberian bahan bentonit dengan tujuan agar posisi elektroda dan tanah mengikat/kuat; 4)pengukuran nilai tahanan pentanahan individual dengan alat ukur eart tester; 5)menggabungkan elektroda yang sudah terpasang dengan sistem secara paralel dan diukur kembali nilai tahanan pembiannya; 6)terakhir pembuatan bak kontrol yang berfunsi sebagai tempat untuk melakukan pengujian nilai resitansi pentanahan di masa yang akan datang. Menurut peraturan Dinas ketenagakerjaan bidang riksa uji proses pemeriksaan dan pengujian pentanahan dilakukan 2 tahun sekali.

Nilai tahanan pembmian dipengaruhi oleh faktor: 1)tahanan jenis tanah, 2) kedalaman dan 3) jenis dan dimensi elektroda pentanahan yang ditunjukan Tabel 1, Tabel .2 dan Gambar 4.

Tabel 1. Resistans Jenis tanah

\begin{tabular}{|l|c|}
\hline \multicolumn{1}{|c|}{ Jenis tanah } & $\begin{array}{c}\text { Resistans jenis }(\boldsymbol{\Omega} \\
\mathrm{m})\end{array}$ \\
\hline Tanah rawa & 30 \\
\hline $\begin{array}{l}\text { Tanah liat \& tanah } \\
\text { ladang }\end{array}$ & 100 \\
\hline Psir basah & 200 \\
\hline Kerikil basah & 500 \\
\hline Pasir \& kerikil kering & 1000 \\
\hline Tanah berbatu & 3000 \\
\hline
\end{tabular}

(Sumber: Putra,2018)

Tabel 2. Kedalaman Elektroda 


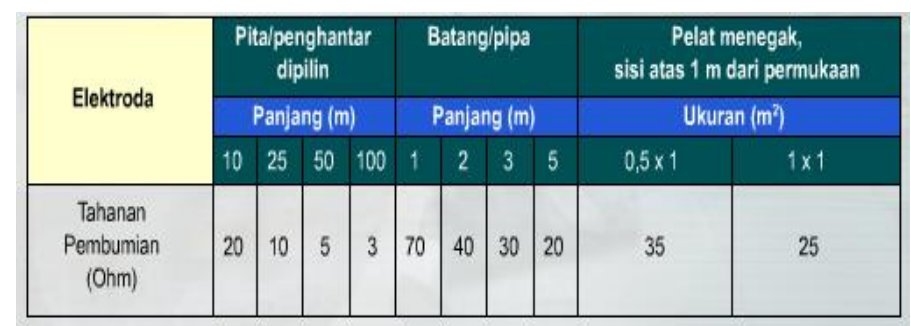

(Sumber: Putra,2018)

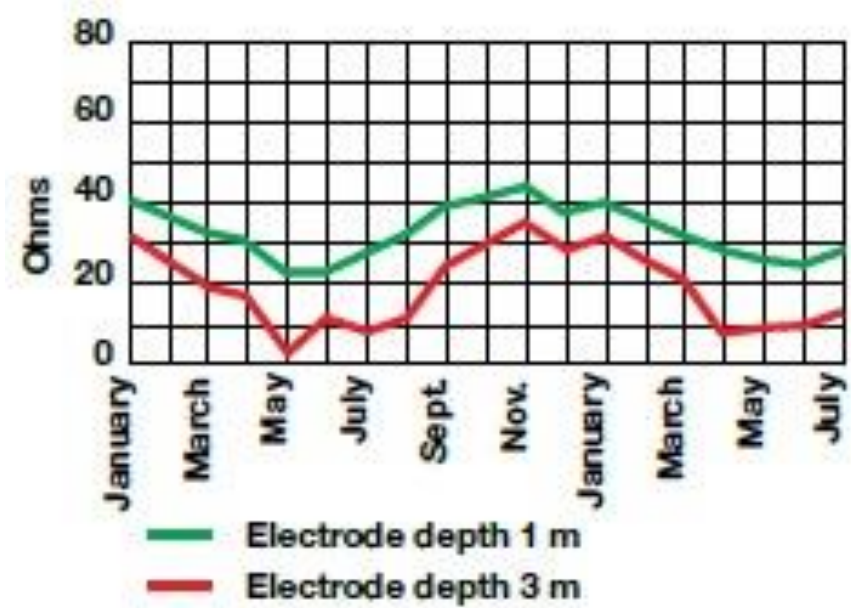

Gambar 4. Kedalaman pentanahan

(Sumber: Martin,2018)

Persamaan (1) merupakan persamaan untuk menghitung nilai tahanan pentanahan dengan dipengaruhi oleh tahanan jenis tanah, kedalaman pemasangan elektroda dan jenis elektroda termasuk dimensi elektroda.

$$
\rho=2 . \pi \cdot a \cdot R \Omega . \mathrm{m}
$$

Dimana:

$\rho$ : Tahanan jenis tanah ( $\Omega . m)$

$\mathrm{a}:$ kedalaman dari elektroda $\mathrm{h}=(3 \mathrm{a} / 4)$

$$
\text { Rparalel }=\frac{R 1 \cdot R 2}{R 1+R 2} \Omega
$$

Persamaan (2) merupakan persamaan matematik untuk menghitung berapa nilai tahanan pentanahan yang sudah dgabungkan antara elektroda yang baru dipasang secara paralel dengan elektroda yang lama terpasang. Sehingga dari hasil perhitungan dan pengujian kita analisa dengan membandingkan apakah terjadi perbedaan yang jauh atau mendekati nilai yang sama.

\section{Hasil Dan Pembahasan}

Pengukuran nilai tahanan pentanahan menggunakan alat ukur Earth Tester dengan metode 3 pole seperti Gambar 5. dengan prosedur pengujian pentanahan seperti yang ditunjukan Gambar 5 sebagai berikut: 1) pasang kabel sesuai dengan gambar 5; 2) tes baterai, jika kondisi level baterainya jelek, maka baterainya harus diganti; 3) tes earth volt dilakukan untuk mengetahui apakah ada kebocoran arus, nilai kebocoran menurut standar adalah maksimal 1 volt; jika hasilnya lebih dari 1 volt, maka indikasi dari nilai pentanahannya kurang baik; pindahkan posisi selector switch earth tester ke posisi pengukuran pentanahan; 4) catat hasil pengujian tahanan pentanahan. 
Dalam melakukan pengukuran tahanan pentanahan tidak boleh hanya dilakukan sekali pengukuran saja, tetapi harus dilakukan beberapa kali sapai didapat hasil pengukuran yang nilainya sama (homogen). Hal ini dikarenakan kondisi tanah tidak seluruhnya homogen. Bila alat ukur Earth Tester yang digunakan jenis digital dimana penunjukan alat ukur tersebut tidak stabil karena angka terahir yang ditampilkan alat ukur tesebut selalu berubah-ubah maka harus menggunakan nilai yang paling mendekati sama.

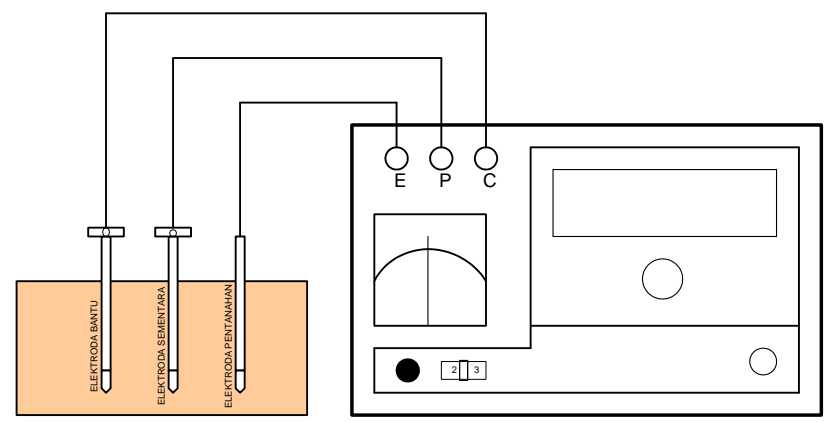

Gambar 5. Pengujian Pentanahan

(Sumber: Sudiartha,2016)

Pengukuran tahanan pentanahan diawali dengan mengukur nilai tahanan pentanahan di Laboratorium Elektronika dan Laboratorium Otomasi sebelum dilakukan perbaikan dengan menambahkan elektroda pentanahan tambahan. Nilai tahanan pentanahan sebelum perbaikan di kedua laboratorium tersebut masing-masing adalah sebesar 18,84 Ohm dan sebesar 10,24 Ohm seperti pada Gambar 6 dan gambar 7. Nilai tersebut jauh melebihi ketentuan PUIL 2011. Oleh karena itu nilai tahanan pentanahan tersebut harus diperbaiki dengan cara memasang elektroda pentanahan tambahan kemudian dihubungkan dengan elektroda pentanahan yang sudah terpasang agar nilai tahanan pentanahan lebih kecil atau sama dengan 5 Ohm. Hubungan antara elektroda pentanahan terpasang dengan elektroda pentanahan tambahan dihubung secara paralel dengan tujuan untuk memperkecil nilai tahanan pentanahan.

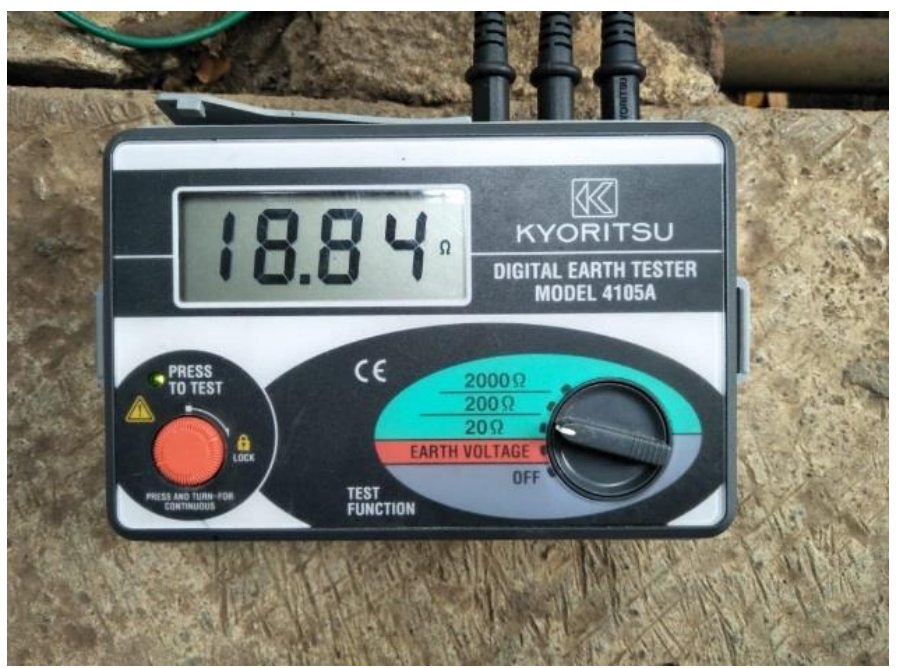

Gambar 6. Hasil pengukuran tahanan pentanahan di Laboratorium Elektronika sebelum perbaikan 


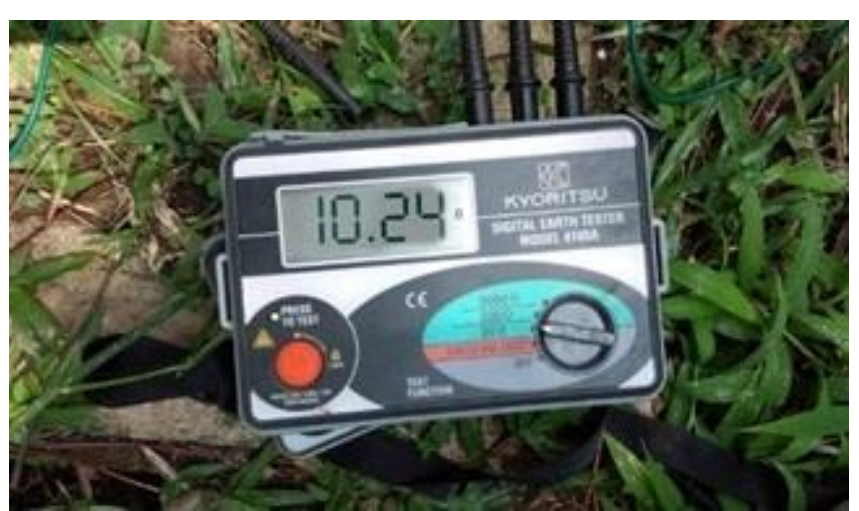

Gambar 7. Hasil pengukuran tahanan pentanahan di Laboratorium Otomasi sebelum perbaikan

Perhtungan tahanan elektroda pentanahan tambahan berdasarkan rumus (1) dengan panjang (h) elektroda yang akan dipasang adalah 4 meter, maka :

$$
h=\frac{3 \cdot a}{4} \quad \text { sehingga } a=\frac{4 \cdot h}{3}=\frac{4 \cdot 4}{3}=\frac{16}{3}=5,3
$$

Dengan demikian tahanan pentanahan elektroda tambahan yang akan dipasang adalah :

$$
R=\frac{\rho}{2 \cdot \pi \cdot a}=\frac{100}{2.3,14.5,3}=3 \mathrm{Ohm}
$$

Perhitungan nilai tahanan pentanahan total (paralel) di Laboratorium Elektronika :

$\mathrm{R} 1=18,84 \mathrm{Ohm}$, sebelum perbaika,

$\mathrm{R} 2=3 \mathrm{Ohm}$, tahanan elektroda tambahan yang akan dipasang,

Maka besarnya nilai tahanan pentanahan paralel antara elektroda pentanahan terpasang dengan elektroda pentanahan tambahan adalah :

$$
\begin{gathered}
R_{\text {paralel }}=\frac{R_{1} \cdot R_{2}}{R_{1}+R_{2}} \\
R_{\text {paralel }}=\frac{R_{1} \cdot R_{2}}{R_{1}+R_{2}}=\frac{18,84 \times 3}{18,84+3}=2,59 \mathrm{Ohm}
\end{gathered}
$$

Perhitungan nilai tahanan pentanahan total (paralel) di Laboratorium Otomasi :

$\mathrm{R}_{1}=10,24 \mathrm{Ohm}$, sebelum perbaika,

$\mathrm{R}_{2}=3 \mathrm{Ohm}$, tahanan elektroda tambahan yang akan dipasang,

Maka besarnya nilai tahanan pentanahan paralel antara elektroda pentanahan terpasang dengan elektroda pentanahan tambahan adalah :

$$
\begin{gathered}
R_{\text {paralel }}=\frac{R_{1} \cdot R_{2}}{R_{1}+R_{2}} \\
R_{\text {paralel }}=\frac{R_{1} \cdot R_{2}}{R_{1}+R_{2}}=\frac{10,24 \times 3}{10,24+3}=2,32 \mathrm{Ohm}
\end{gathered}
$$

Nilai perhitungan di atas merupakan perancangan elektroda pentanahan tambahan dan nilai tahanan pentanahan yang dikehendaki agar nilainya tidak melebihi $5 \mathrm{Ohm}$ sesuai ketentuan yang dipersyaratkan PUIL 2011.

Karena nilai tahanan pentanahan dipengaruhi oleh beberapa factor, maka nilai tahanan pentanahan real setelah perbaikan belum tentu sama nilainya dengan hasil perancangan.

Langkah selanjtnya adalah melakukan pengboran untuk penempatan elektroda batang (Gambar 7). Pengeboran tanah diperlukan karena bahan elektroda batang yang akan dipasang terbuat dari tembaga murni. Bila pemasangannya dilakukan dengan cara dipukul langsung maka batang tembaga tersebut bisa 
bengkok bahkan bisa patah. Dalamnya lubang pengeboran disesuaikan dengan Panjang elektroda pentanahan yang akan dipasang, karena bila terlalu dalam makan aka nada celah dan dikhawatirkan saat memasukkan elektroda pentanahan ada kemungkinan lepas masuk ke dalam sehingga sulit untuk mengambil atau mengangkat elektroda pentanahan tersebut.

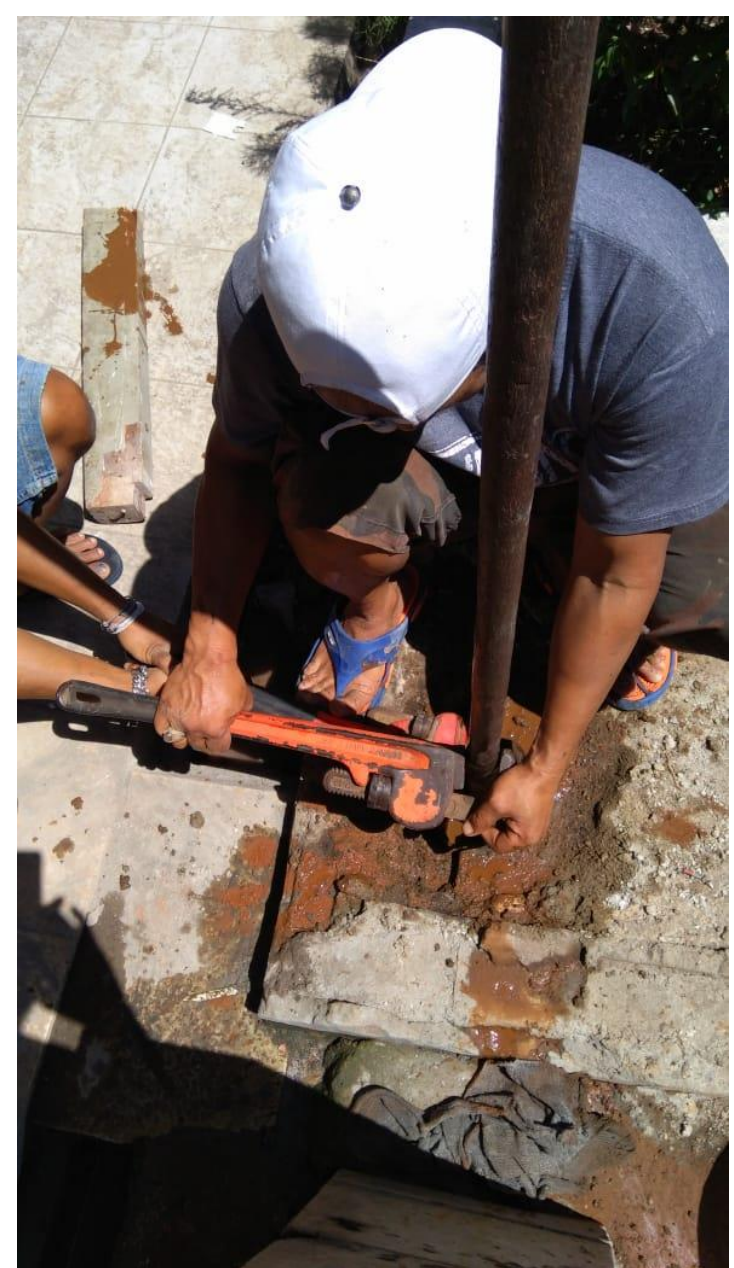

Gambar 8. Proses pengeboran

Pada lubang pengeboran dipasang elektroda batang, kemudian ditungkan bentonite yang telah diencerkan pada celah antara elektroda batang dengan tanah sekitarnya agar konduktifitas elektroda pentanahan dengan tanah sekitarnya terhubung dengan baik (Gambar 8). 


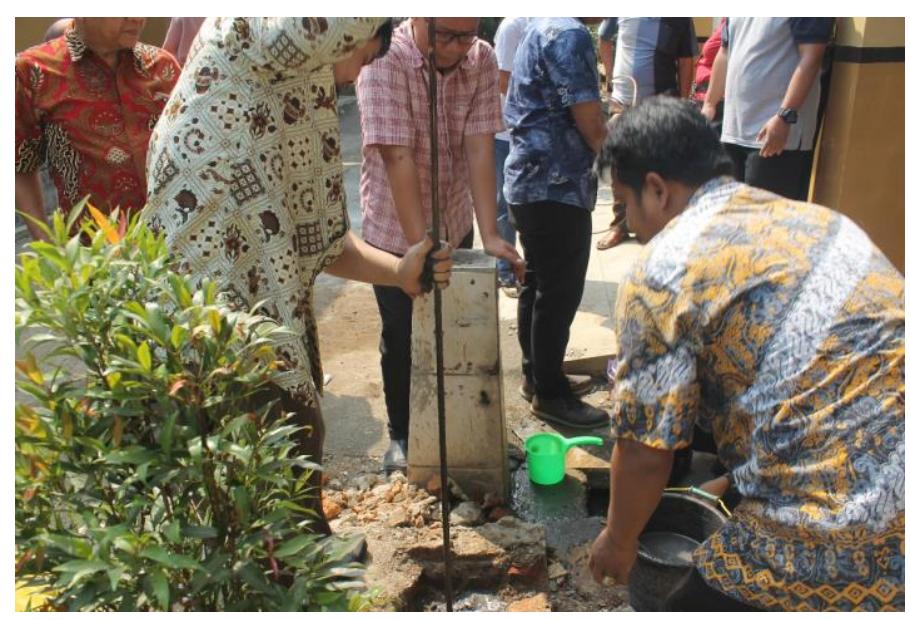

Gambar 9. Pemasangan elektroda batang

Setelah elektroda batang tambahan selesai dipasang maka jangan langsung dihubungkan ke elektroda pentanahan terpasang. Sebaiknya menunggu bentonite mengering, karena bila bentonite belum mengering langsung melakukan penyambungan maka terjadi goyangan sehingga bisa membentuk celah antara elektroda batang dengan tanah sekitarnya dan hal ini bisa menyebabkan konduktifitas buruk.

Langkah berikutnya adalah penyambungan elektroda tambahan dengan elektroda terpasang (Gambar 9) di Laboratorium Elektronika dan di Laboratorium Otomasi.

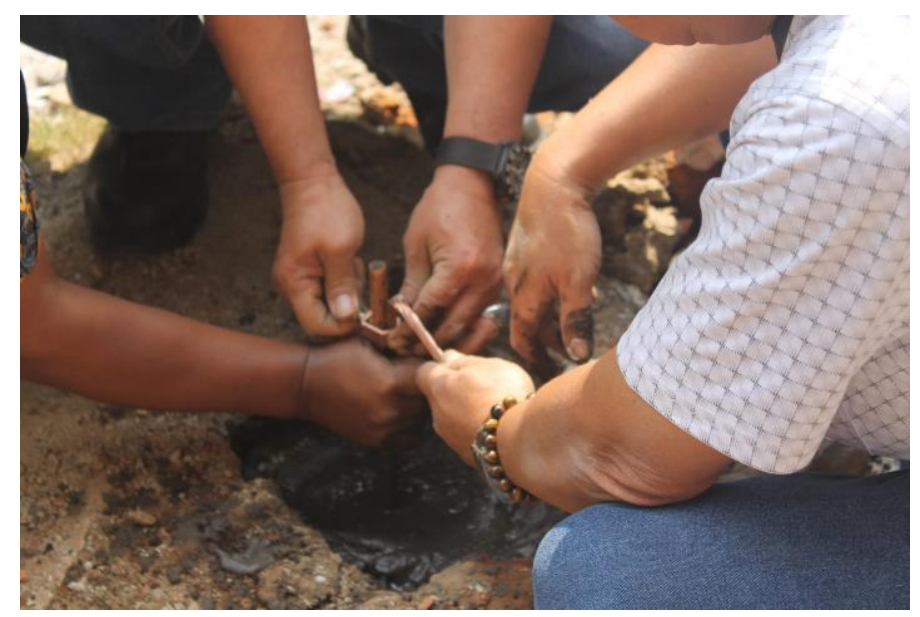

Gambar 10. Penyambungan elektroda

Setelah selesai penyambungan kedua elektroda pentanahan, maka selanjutnya melakukan pengukuran nilai pentahanah elektroda paralel (nilai tahanan total setelah perbaikan).

Hasil pengukuran tahanan pentanahan paralel antara elektroda pentanahan terpasang dengan elektroda pentanahan tambahan di Laboratorium Elektronika setelah dilakukan penyambungan elektroda tambahan dengan elektroda terpasang adalah 2,83 Ohm (Gambar 10). Hal ini sudah memenuhi standar PUIL 2011. 


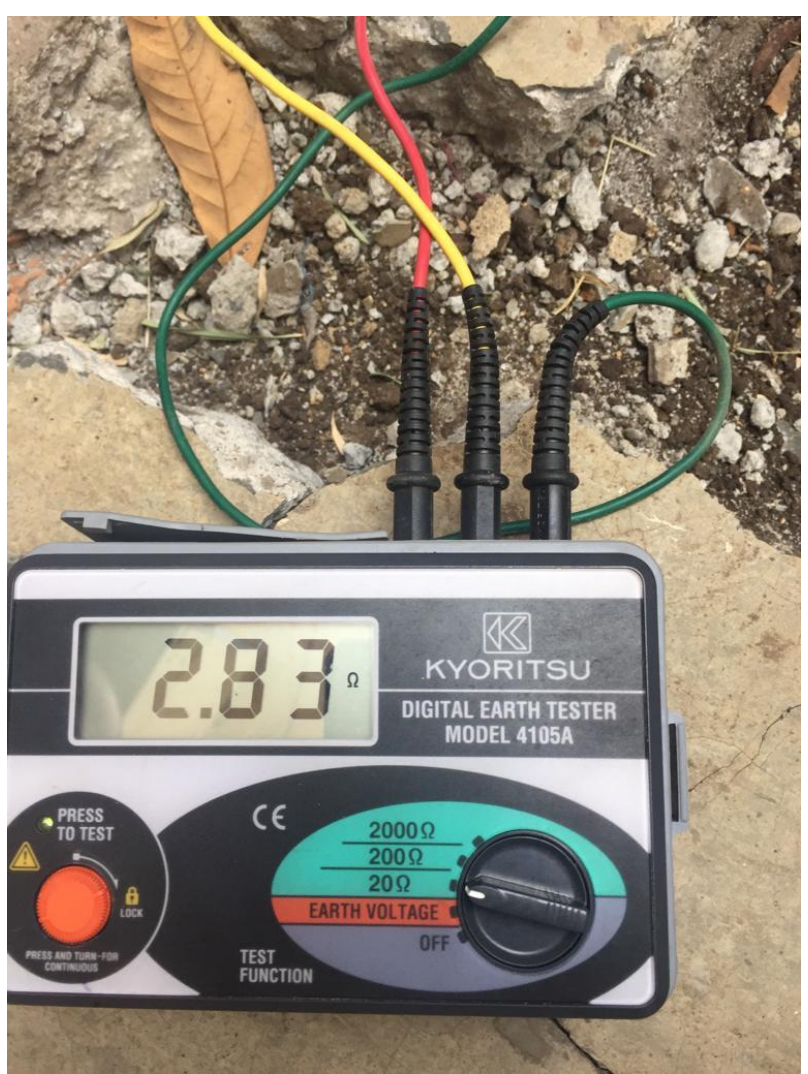

Gambar 11. Hasil pengukuran nilai tahanan elektroda paralel di Laboratorium Elektronika setelah perbaikan.

Hasil pengukuran tahanan pentanahan paralel di Laboratorium Otomasi setelah dilakukan penyambungan elektroda tambahan dengan elektroda terpasang adalah 2,72 Ohm (Gambar 11). Hal ini sudah memenuhi standar PUIL 2011.

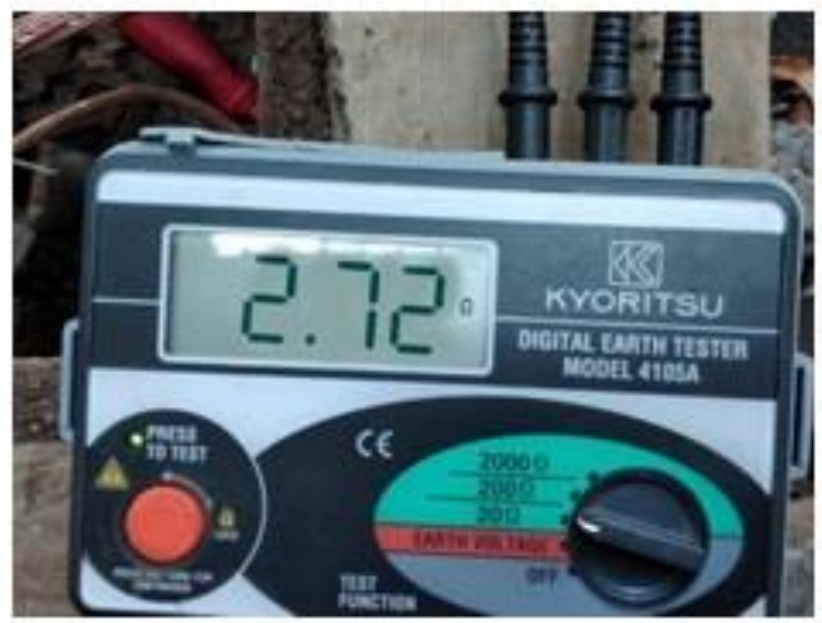

Gambar 12. Hasil pengukuran nilai tahanan elektroda paralel di Laboratorium Otomasi setelah perbaikan.

Dari hasil pengukuran nilai tahanan pentanahan di laboratorium Elektronika dan Laboratorium Otomasi maka dapat dihitung nilai tahanan pentanahan tambahan yang dipasang. 


$$
\begin{gathered}
R_{\text {paralel }}=\frac{R_{1} \cdot R_{2}}{R_{1}+R_{2}} \\
R_{2}=\frac{R_{1} \times R_{\text {paralel }}}{R_{1}-R_{\text {paralel }}}
\end{gathered}
$$

Nilai tahanan pentanahan tambahan di Laboratorium Elektronika :

$$
R_{2}=\frac{18,84 \times 2,83}{18,84-2,83}=3,3 \mathrm{Ohm}
$$

Nilai tahanan pentanahan tambahan di Laboratorium Otomasi :

$$
R_{2}=\frac{10,24 \times 2,72}{10,24-2,72}=3,7 \mathrm{Ohm}
$$

Nilai resistansi pentanahan di laboratorium Elektronika dan Laboratorium Otomasi berdasarkan perancangan sebesar $3 \mathrm{Ohm}$. Dengan demikian perancangan elektroda tambahan di kedua laboratorium berhasil dengan baik, hanya ada selisih sedikit tetapi berhasil memperkecil nilai tahanan pentanahan. Selain perancangan, juga cara pemasangan instalasi pentanahan yang mempengaruhi keberhasilan penelitian ini yaitu dalam hal pemberian bentonite dalam pemasangan elektroda pentanahan, dan cara pengambungan kawat penghantar dengan elektroda pentanahan. Pemberian bentonite bisa merapatkan celah antara elektroda pentanahan dengan tanah di sekitarnya. Cara penyambungan yang dilakukan dengan baik maka bisa memperkecil hambatan yang terjadi pada sambungan tersebut.

\section{Kesimpulan}

Berdasarkan hasil dan pembahasan renovasi sistem pentahanan instalasi lsitrik di Laboratorium Elektronika dan Laboratorium Otomasi SMK Negeri 1 Cimahi dengan cara memasang elektroda tambahan berupa elektroda jenis batang dengan bahan tenbaga panjang 4 meter, berhasil memperbaiki atau memperkecil nilai tahanan pentanahan. Nilai tahanan pentanahan di Laboratorium Elektronika sebelum perbaikan sebesar 18,84 Ohm dan setelah perbaikan menjadi 2, $83 \mathrm{Ohm}$. Demikian juga niali tahanan pentanahan di Laboratotium Otomasi, sebelum perbaikan sebesar 10,24 Ohm dan setelah perbaikan sebesar 2,72 Ohm. Dengan demikian perencanaan elektroda pentanahan tambahan di kedua laboratorium tersebut berhasil dengan baik karena dapat menurunkan nilai tahanan pentanahan sehingga memenuhi persyaratan PUIL 2011.

\section{Saran}

Dalam penelitian ini ada tahapan yang terlewat yaitu pengukuran nilai tahanan pentanahan tambahan yang dipasang, oleh karena itu untuk mengetahui nilai tahanan pentanahan tambahan yang sebenarnya dilakukan dengan pertitungan. Yang perlu diperhatikan dalam pemasangan instalasi pentanahan selain perancangan lektroda pentahannya juga harus memperhatikan cara pemasangannya. Penelitian ini bisa dilanjutkan dengan meneliti besarnya tegangan sentuh yang terjadi pada rangka peralatan bila terjadi arus bocor akibat kegagalan isolasi.

\section{Ucapan Terima Kasih}

Ucapan terimakasih disampaikan kepada P3M Politeknik Negeri Bandung yang telah mendanai penelitian ini melalui skema Pengabdian kepada Masyarakat tahun anggaran 2019 dengan kontrak Nomor: 352.8/PL1.R7/PM/2019. 


\section{Daftar Pustaka}

Achmad Budiman, "Analisa Perbandingan Tahanan Pentanahan Peralatan Elektroda Pasak pada Gedung Teknik Universitas Borneo Tarakan “,Jurnal Nasional Teknik Elektro Vol 6, No. 3, November 2017 Universitas Borneo Tarakan.

Deni Setiawan, 'Analisis Pengaruh Penambahan Garam dan Arang Sebagai Soil Treatment dalam Menurunkan Tahanan Pentanahan Variasi Kedalaman Elektroda' Transient Jurnal ilmiah Teknik Elektro, vol. 7, no. 2, 12 September 2018, UNDIP.

Dian Eka Putra, 'Pengukuran Grounding SDP Panel Distribusi Instalasi Rekam Medis RSUP Dr. Mohammad Hoesin Palembang' Jurnal Ampere, Volume 3, No.1, Juni 2018, Universitas Palembang.

Fr1ely Didit Sukardi1, Prototipe Pengaman Peralatan Instalasi Listrik dan Tegangan Sentuh Bagi Manusia dengan ELCB ( Earth Leakege Circuit Breaker), Jurnal Teknologi Elekterika No.2, Vol.16, 2019.

Hutauruk,T.S,"Pengetanahan netral sistem tenaga \& pengetanahan peralatan”, Erlangga, Jakarta, 1999

I Wayan Sudiartha, "Analisis Pengaruh Jenis Tanah Terhadap Besarnya Nilai Tahanan Pentanahan", Jurnal Logic Volume 16 No. 1, Maret 2016, Politeknik Negeri Bali.

Makmur Saini, 'Pengembangan Sistem Penangkal Petir dan Pentanahan Elektroda Rod dan Plat', Journal INTEK, Volume 3, Nomor 2, 2016, Politeknik Negeri Ujung Pandang.

Managam Rajagukguk, 'Penentuan Nilai Impedansi Elektroda Batang Tunggal Berdasarkan Karakteristik Response Impuls', Jurnal ELKHA Vol 2, Vol. 2, Juli 2010, Universitas Tanjungpura Pontianak.

Muhammad Suyanto, 'Pengukuran Sistem Pentanahan pada Rumah Tinggal Sebagai Upaya Perbaikan Grounding untuk Mengurangi Efek Tegangan Sentuh', Jurnal Teknik Vol 28 No 3 Oktober 2015 Universitas Pancasila

SNI 0225-2011, "Persyaratan Umum Instalasi Listrik 2011 (PUIL 2000)" Badan Standardisasi Nasional, Jakarta 2011.

SNI 04-0225-2000, “Persyaratan Umum Instalasi Listrik 2000 (PUIL 2000)" Badan Standardisasi Nasional, Jakarta 2000.

Thamrin Siahaan, Studi Pentanahan Peralatan dan Sistem Instalasi Listrik pada Gedung Kantor BICT PT. Pelindo I (Persero) Belawan, Jurnal Teknologi Energi, Jurnal Teknik Elektro Volume VIII, Nomor 2, September 2019

Yul Martin, 'Pengaruh Pencampuran Gypsum Sebagai Zat Aditif Untuk Penurunan Nilai Tahanan Grounding Pada Elektroda Batang Tunggal', Seminar nasional teknik elektro 2018 Universitas lampung. 